\title{
Comparison among Different Screening Tests for Diagnosis of Adolescent Hypertension
}

\author{
Silvia Totaro, ${ }^{1}$ Franco Rabbia, ${ }^{1}$ Ivana Rabbone, ${ }^{2}$ Michele Covella, ${ }^{1}$ Elena Berra, \\ Chiara Fulcheri, ${ }^{1}$ Silvia Di Monaco, ${ }^{1}$ Elisa Testa, ${ }^{1}$ and Franco Veglio ${ }^{1}$ \\ 1 "Città della Scienza e della Salute di Torino", Hypertension Unit, Department of Medical Sciences, \\ University of Turin, 10126 Torino, Italy \\ 2 "Città della Scienza e della Salute di Torino", Pediatric, University of Turin, 10126 Torino, Italy \\ Correspondence should be addressed to Silvia Totaro; s.totaro84@gmail.com
}

Received 22 April 2013; Accepted 2 June 2013

Academic Editors: J. Johnson and M. Rosenberg

Copyright (C) 2013 Silvia Totaro et al. This is an open access article distributed under the Creative Commons Attribution License, which permits unrestricted use, distribution, and reproduction in any medium, provided the original work is properly cited.

\begin{abstract}
The diagnosis of childhood hypertension based upon percentile tables proposed by the international guidelines is complex and often a cause of underdiagnosis, particularly among physicians who have not had specific training in the field of adolescent hypertension. The use of a simple and accurate screening test may improve hypertension diagnosis in adolescents. The aim of our study is to compare the different screening methods currently used in the literature to improve the diagnosis of childhood hypertension. We have conducted a cross-sectional population-based study of 1412 Caucasian adolescents among students of public junior high schools of Turin, Italy. In this population we have defined the hypertensive status with four different screening tests: BPHR, Somu's equations, Ardissino, and Kaelber methods. Finally, we compared the diagnostic accuracy of the 4 screening tests with the gold standard. Our analysis identifies in BPHR the test which combines ease of use and diagnostic accuracy.
\end{abstract}

\section{Introduction}

Prevalence of childhood hypertension is constantly rising [1]; early detection is therefore important in order to reduce progression of adult hypertension, premature development of organ damage and to establish early treatment of all associated risk factors.

In adolescents blood pressure values vary with height, age, and gender, making it impossible to utilize a specific blood pressure level to define hypertension, as in adults.

The identification of blood pressure thresholds for any child implies the use of sex-specific height percentiles tables and subsequently tables specifying systolic and diastolic 90th and 95th percentiles for different sex, age, and height percentiles. Children with average of systolic or diastolic blood pressure $\geq 90$ th and $<95$ th percentiles are classified as having high-normal blood pressure; hypertension is defined when systolic and/or diastolic blood pressure are persistently $\geq 95$ th percentile [2].

The practical complexity of this method is an essential cause of underdiagnosis for this condition.
Throughout the years, different criteria have been suggested in order to simplify diagnosis and therefore reduce under-diagnosis.

\section{Aim}

We have looked for the different screening tests currently used in the literature in order to compare their accuracy in the diagnosis of hypertension in adolescents. The aim of our study is to propose a critical analysis and a comparison among different screening methods currently available in order to find the simplest and most accurate one.

\section{Methods}

We have conducted a cross-sectional population-based study of 1412 Caucasian adolescents among students of public junior high schools of Turin, Italy. Informed consent from adolescents and their parents was obtained. The investigation conforms to the principles outlined in the Declaration of 
Helsinki (1964) and Declaration of Tokyo (1975), as revised in 1983.

Adolescents' age range was 11-18 years and they were homogeneous for sex (682 females and 730 males).

Anthropometric measurements, such as height and weight, were performed when subjects were standing without shoes and in light clothing with a stadiometer and electronic scale, respectively.

BMI was defined as weight $(\mathrm{kg})$ divided by height $(\mathrm{m})$ squared.

Blood pressure was the result of the average of three measurements at $1 \mathrm{~min}$ intervals obtained after $5 \mathrm{~min}$ of rest and in a warm and heated room. Measurements were taken with a mercury sphygmomanometer using appropriate cuff sizes. The fifth Koroktoff sound was considered as the measure of diastolic blood pressure.

Hypertension was defined according to recommendations of the European Society of Hypertension of 2009 [2].

Four different indexes were applied in our population: blood pressure/height ratio (BPHR), [3], Somu's equations, [5], Ardissino's table [4], and Kaelber's table, [6] (Table 1). BPHR was calculated for systolic and diastolic pressure as pressure $(\mathrm{mmHg})$ to height $(\mathrm{cm})$ ratio. Patients were considered suffering from hypertension if their ratio, were over the suggested cutoff. BPHR requires only four thresholds (two for male and two for female) for diagnosis. Somu's equations identify the 95th pressure percentile using the formula $100+$ (age in years $\times 2$ ) (for children between 1 and 17 years) for the systolic pressure. The formulae $60+$ (age in years $\times 2$ ) (for children between 1-10) and 70+ age in years (for children between 11 and 17) are used for diastolic pressure. One of Somu's equation strengths is the need to memorize only one simple formula.

To identify 95th percentile with Ardissino's and Kaelber's methods we have used the thresholds of their tables: in the table used by Ardissino the thresholds vary with height while in the table provided by Kaelber they vary according to age. These last two methods are easier to use when compared to the one provided in the guidelines; however they still require the physician to have tables, which may represent a disadvantage over BPHR and Somu's equation.

True positives and true negatives of the screening tests applied in our population against the gold standard were calculated. Eventually, sensibility, specificity, and accuracy of the different tests were compared.

ROC curves were drawn to show the overall discriminatory power of the screening tests.

Means and standard deviations for descriptive variables and proportions for categorical variables were calculated. The statistical analysis was performed using the SAS package (SAS Statistical Software, Cary, NC, USA). A $P$ value of $<0.05$ was considered statistically significant.

\section{Results}

The prevalence of hypertension in our population is $17 \%$.

Among the screening tests, Somu's equations and Ardissino's table have the best accuracy (both 95\%) but they tend to underestimate the prevalence: in fact, the thresholds
TABLE 1: Current screening test for childhood hypertension.

(a)

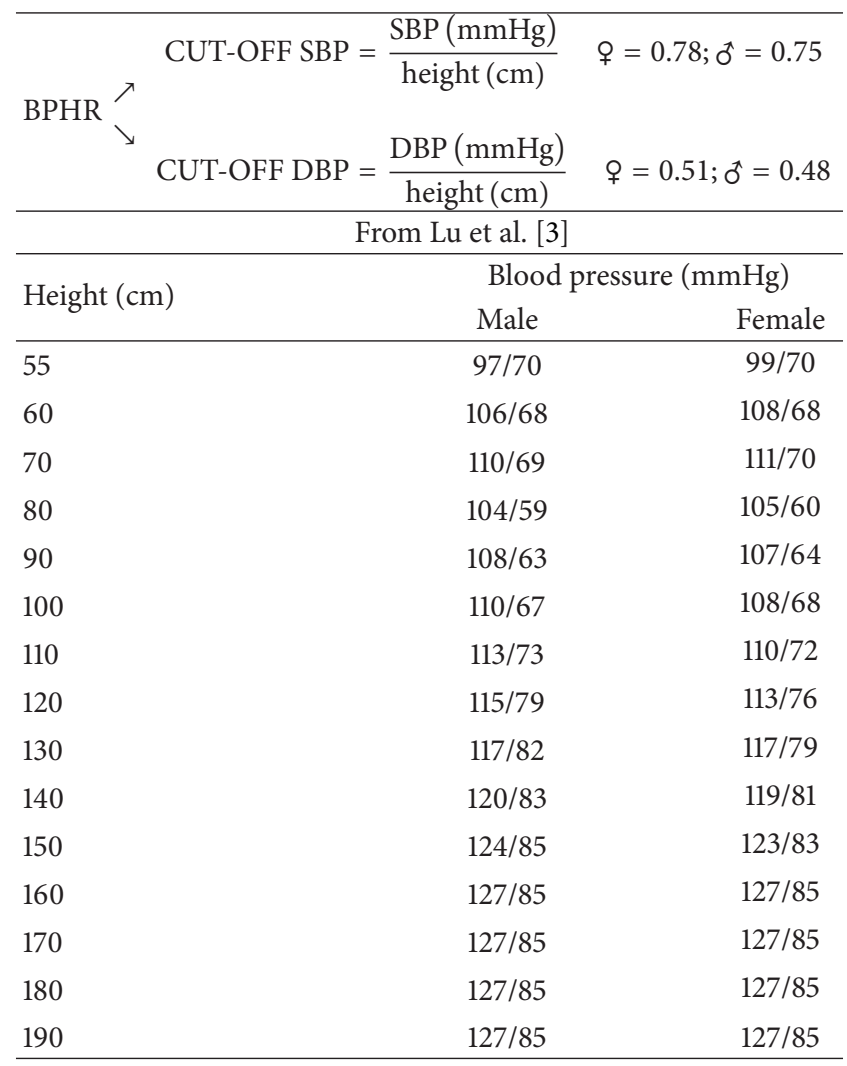

$\frac{\text { Modified from Ardissino et al. [4] }}{\text { (b) }}$

\begin{tabular}{lcc}
\hline SBP $\left(95^{\circ}\right.$ percentile $)$ & $1-17$ years: $100+($ years $\times 2)$ \\
DBP $\left(95^{\circ}\right.$ percentile $)$ & $1-10$ years: $60+($ years $\times 2)$ \\
& \multicolumn{1}{c}{$11-17$ years: $70+($ years $)$} \\
\hline Age (y) & From Somu et al. [5] \\
\hline 3 & Blood pressure $(\mathrm{mmHg})$ \\
4 & Male & Female \\
5 & $100 / 59$ & $100 / 61$ \\
6 & $102 / 62$ & $101 / 64$ \\
7 & $104 / 65$ & $103 / 66$ \\
8 & $105 / 68$ & $104 / 68$ \\
9 & $106 / 70$ & $106 / 69$ \\
10 & $107 / 71$ & $108 / 71$ \\
11 & $109 / 72$ & $110 / 72$ \\
12 & $111 / 73$ & $112 / 73$ \\
13 & $113 / 74$ & $114 / 74$ \\
14 & $115 / 74$ & $116 / 75$ \\
15 & $117 / 75$ & $117 / 76$ \\
16 & $129 / 75$ & $119 / 77$ \\
17 & $120 / 76$ & $120 / 78$ \\
$\geq 18$ & $120 / 78$ & $120 / 78$ \\
\hline & $120 / 80$ & $120 / 78$ \\
& $120 / 80$ & \\
\hline
\end{tabular}


of these two methods favor the specificity (both 99\%) over the sensibility (resp. $73 \%$ and 78\%). Kaelber's method has the worst accuracy (80\%); despite the highest sensibility (100\%) its specificity is low (76\%). The screening test proposed by $\mathrm{Lu}$ et al. is a good compromise between sensibility (94\%) and specificity $(86 \%)$, with an accuracy of $87 \%$.

The ROC curves of BPHR have an AUC (area under the curve) greater than $95 \%$ both for systolic and diastolic values and for both genders.

\section{Discussion}

In conclusion, considering the need of an easy and rapid screening test to diagnose adolescent hypertension, Kaelber's test should be considered as the best screening test because of its high sensibility; by contrast it is associated to the highest number of false positive cases; this can bear important psychological implications in young patients and their parents. Our analysis, therefore, identifies in BPHR the best compromise between sensibility (important feature of a screening test) and accuracy. Moreover, the BPHR is an easy-to-apply test that allows the identification of hypertensive children with only four thresholds and therefore can be used in any setting. This method has a wide applicability: it was originally proposed in the Chinese population but it has subsequently been validated in Caucasian adolescents [7].

It is important to underline that BPHR and the other tests should be used for screening purposes, and a positive result must be confirmed with the traditional method.

Further studies are necessary to extend the scope of the investigation in children younger than 11 years old.

\section{References}

[1] J. Feber and M. Ahmed, "Hypertension in children: new trends and challenges," Clinical Science, vol. 119, no. 4, pp. 151-161, 2010.

[2] E. Lurbe, R. Cifkova, J. K. Cruickshank et al., "Management of high blood pressure in children and adolescents: recommendations of the European Society of Hypertension," Hipertension y Riesgo Vascular, vol. 27, no. 2, pp. 47-74, 2010.

[3] Q. Lu, C. M. Ma, F. Z. Yin, B. W. Liu, D. H. Lou, and X. L. Liu, "How to simplify the diagnostic criteria of hypertension in adolescents," Journal of Human Hypertension, vol. 25, no. 3, pp. 159-163, 2011.

[4] G. Ardissino, M. Bianchetti, M. Braga et al., "Recommendations on arterial hypertension in children. The Child Project," Italian Heart Journal, vol. 5, supplement 5, pp. 398-412, 2004.

[5] S. Somu, B. Sundaram, and A. N. Kamalanathan, "Early detection of hypertension in general practice," Archives of Disease in Childhood, vol. 88, no. 4, article 302, 2003.

[6] D. C. Kaelber and F. Pickett, "Simple table to identify children and adolescents needing further evaluation of blood pressure," Pediatrics, vol. 123, no. 6, pp. e972-e974, 2009.

[7] F. Rabbia, I. Rabbone, S. Totaro et al., "Evaluation of blood pressure/height ratio as an index to simplify diagnostic criteria of hypertension in Caucasian adolescents," Journal of Human Hypertension, vol. 25, no. 10, pp. 623-624, 2011. 


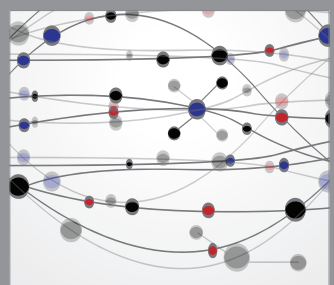

The Scientific World Journal
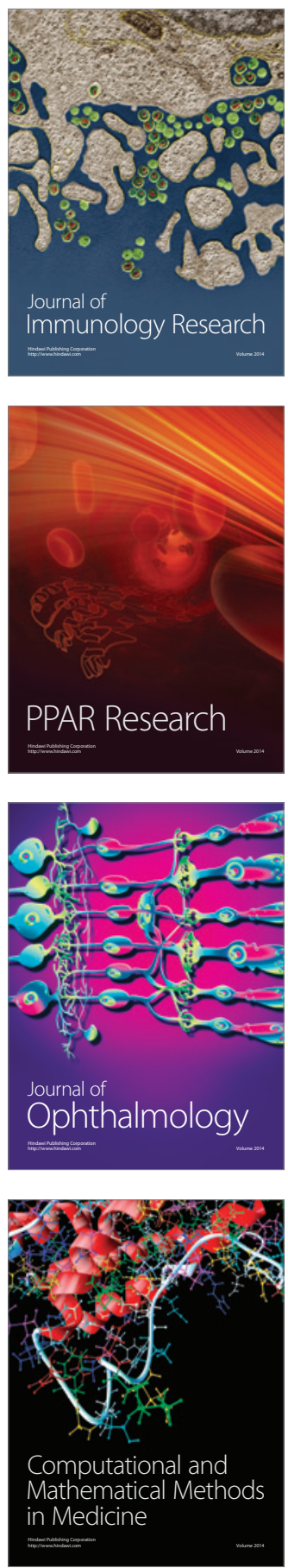

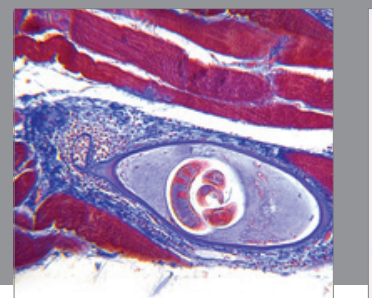

Gastroenterology

Research and Practice
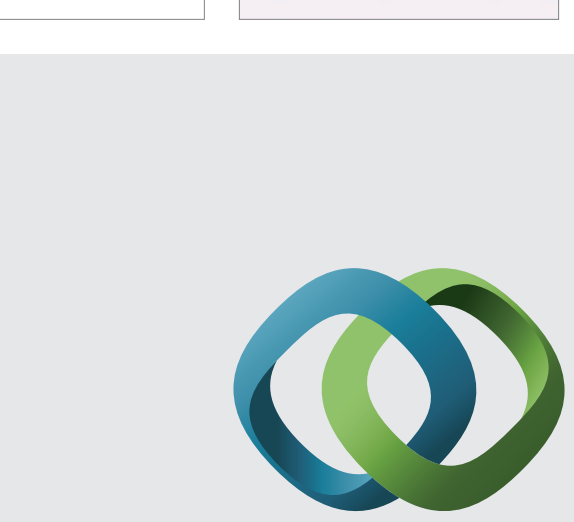

\section{Hindawi}

Submit your manuscripts at

http://www.hindawi.com
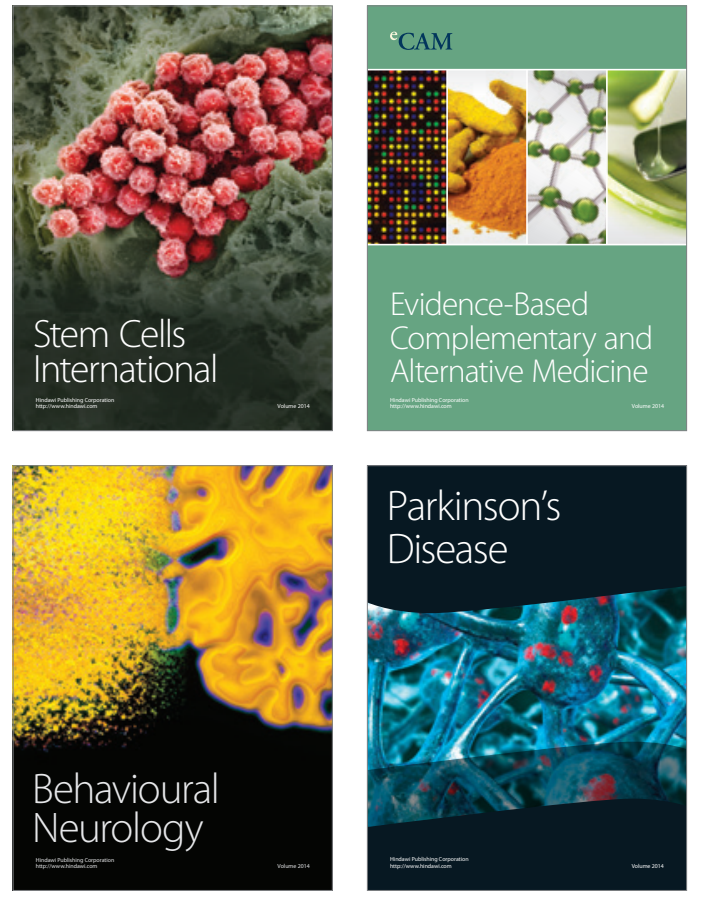
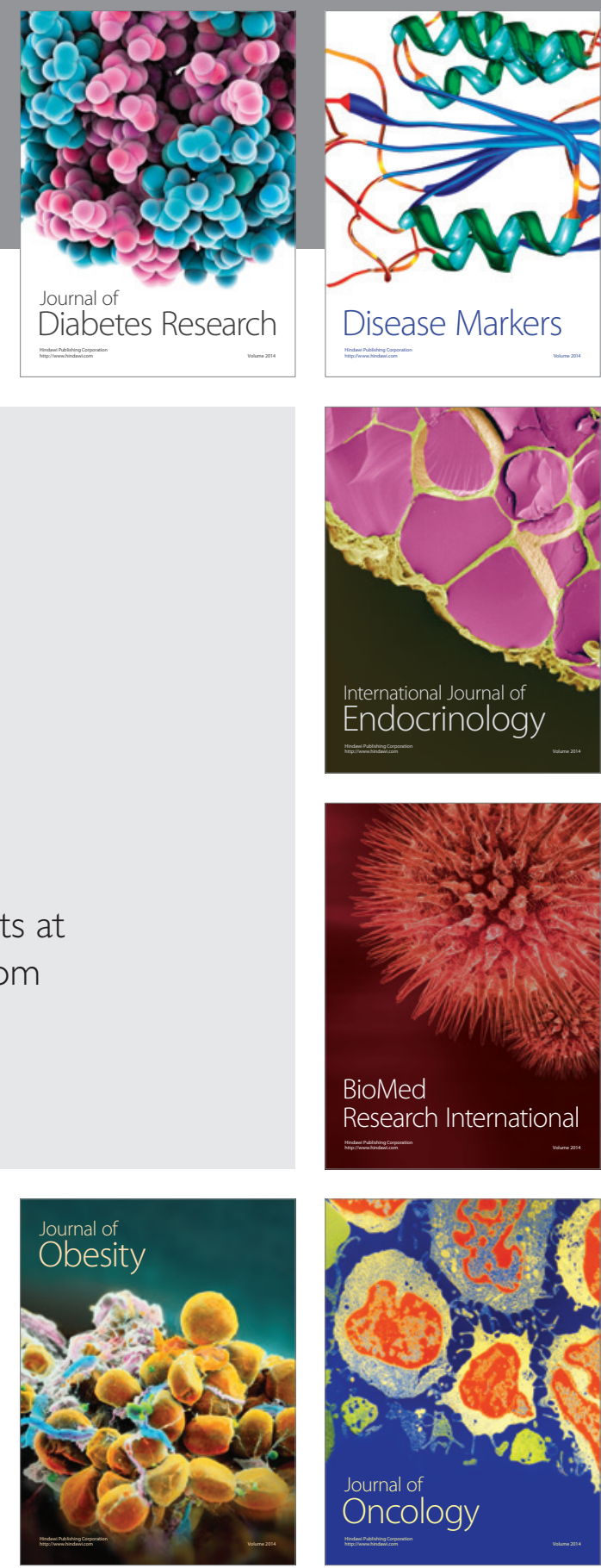

Disease Markers
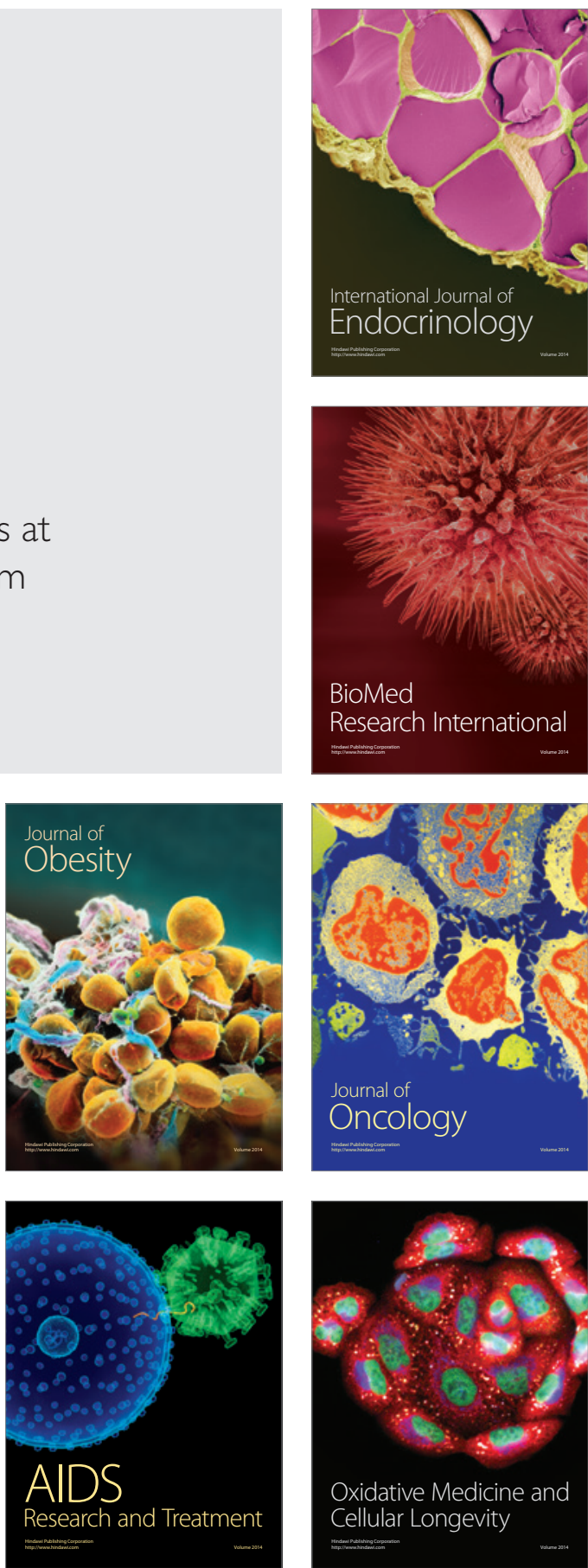